\title{
¿Qué es Logística?
}

Por Manuel Rico

"Es el proceso de gerenciar estratégicamente el movimiento y "almacenamiento" de bienes, servicios, valores e información desde los proveedores a través de las organizaciones hasta el cliente final, sobre los principios de Rentabilidad y Responsabilidad social"

\section{¿Para qué sirve la logística?}

Por Bladimir Ramírez

"Logística es hacer referencia al manejo de todas las actividades que facilitan el movimiento de productos mediante coordinación de la oferta y la demanda en la optimización de la utilidad en el tiempo y la producción, para ofrecer el producto adecuado en el lugar preciso con la cantidad requerida en el tiempo justo y a un costo adecuado.

Hoy en día, no sólo las empresas grandes son las que deben acoplarse a la nueva tecnología o a las nuevas corrientes industriales; actualmente, esta tarea también la comparten empresas pequeñas y medianas. Una buena organización consta de una adecuada integración entre el aprovisionamiento, producción y distribución.

Una red logística asegura la buena planificación dentro de la empresa, ya que se entiende como red logística la integración de cada una de las áreas físicas dentro de la empresa a través de los cuales se genera el flujo de materiales, que a su vez se integra con la red de información generada por pedidos a proveedores, pedidos de clientes, inventarios, plazos de entrega, estadísticas y la contabilización de este flujo de información. La interdependencia entre el costo total y la logística radica fundamentalmente en la minimización de costos, pues no podemos olvidar que adicional a estos conceptos también tenemos que integrar un modelo de costos adecuado a la empresa y que nos lleve a la minimización de estos. Si se lleva a cabo una correcta implementación de un modelo de costos internos de producción será muy importante para la detección de errores a tiempo." 


\section{La logística desde el punto de vista de sus docentes}

\author{
Por Luz Angela Villanueva
}

"Al abordar el tema de la logística, es preciso delimitar la perspectiva desde la cual se pretende analizar. Podríamos comenzar por expresar que, en el sentido estrictamente básico, la logística hace referencia a la organización sistemática de pasos, actividades, etapas, estrategias, políticas u otros aspectos de un proceso, definiendo los detalles del mismo y en función de obtener unos resultados eficientes y eficaces. Paralelamente, al trasladar el término a un escenario de mayor complejidad, encontramos que éste es empleado técnicamente en las disciplinas académicas orientadas a formar personal especializado en gestionar cadenas de abastecimiento Acompañado de otro elemento como Logística de Exportación de procesos comercial entre otros; este segundo se pretende mejorar, ordenar, desarrollar e implementar desde una lógica organizativa. Así pues, la "logística de exportación" pretende implementar mecanismos de orden sistemático para la gestión de entrega de una mercancía desde origen hacia un destino determinado en algún lugar del mundo, la estructura militar aplica procesos logísticos a sus estrategias y tácticas para tener éxito en sus operaciones castrenses. No obstante, para tener una visión más amplia de la logística, debemos referirnos también al contexto empresarial, dado que las organizaciones impulsan procesos logísticos tanto en el ámbito administrativo, operativo y estratégico-comercial; para ello, diseñan planes estratégicos, trazan objetivos en producción, además de gestionar estrategias de comercialización cuyo resultado se deberá en un alto porcentaje al empleo adecuado de las técnicas que en materia logística se utilicen. Con base en lo anterior, podemos deducir que la logística es un proceso, actividad, técnica, mecanismo amplio y complejo inmerso en todas nuestra acciones; además de ser una herramienta de gestión que refleja que tan organizados, precisos o efectivos somos en el contexto en aquel a estemos desarrollando".

\section{La logística como disciplina integral}

\section{Por Edgar Devia}

"Hoy en día en el ambiente laboral, la formación en logística es una competencia fundamental como lo son la informática y el inglés. Quien tenga estos tres conocimientos tiene una gran ventaja y marca la diferencia entre sus demás competidores.
La logística se puede aplicar con eficiencia en todos los campos y empresas u organizaciones, ello explica la creciente demanda laboral de los tecnólogos en logística, pues las empresas necesitan con urgencia repotencializarse ante la globalización, para lograr mayor competitividad, para en esencia contar con un recurso humano formado y capacitado en la disciplina logística. La logística está presente en todas las actividades humanas y, desde luego, en nuestra vida diaria, por ello se dice que la logística no es todo pero está en todo.

Las empresas que tengan bien estructurados sus sistemas logísticos desde el principio y hasta el más alto nivel de la organización, tienen asegurada su sostenibilidad, rentabilidad y progreso, pues la logística bien aplicada les proporcionará la eficacia, efectividad y competitividad suficientes para su desarrollo empresarial. La logística en nuestro territorio colombiano ya que no es una simple moda sino una realidad.

Quienes nos hemos dedicado al estudio, enseñanza y aplicación de la disciplina logística podemos afirmar, sin temor a equivocarnos, que esta es una disciplina integral, la cual debe estudiarse con profundidad permanentemente e incluirse en todos los programas académicos de la educación superior, dentro del área de formación básica profesional.

El estudio de la logística no solamente proporciona conocimientos, destrezas o habilidades y estrategias para actuar con éxito en el campo militar y empresarial sino que ayuda a formar con actitud positiva en el plano personal, con base en la planificación y organización, lo cual se refleja en el cumplimiento, la puntualidad, la responsabilidad y la calidad en todas las actividades que realizamos. Desde luego que cuando asimilamos suficientemente esta disciplina, convirtiéndonos en logísticos, esta nueva situación puede convertirse en una especie de tortura, por cuanto en nuestro país todavía no hay las condiciones plenas para disfrutar esta nueva vida. Se necesita mucho todavía para ampliar la cobertura de aplicación al 100\% y cambiar la mentalidad y el comportamiento de las personas ya que se necesita un cambio de actitud hacia lo positivo. La necesidad de este cambio se demuestra cuando con solo preguntar lo hacemos en forma negativa diciendo: ¿usted no puede hacerme el favor de...? pero, ¿entendemos que esto es un proceso que requiere tiempo y trabajo? Debemos ir eliminando viejas costumbres, empezando por las más simples como el incumplimiento a las citas o a las regiones de trabajo en donde muy poco se cumple con la hora indicada; a veces, inconscientemente, estamos promoviendo 
el incumplimiento cuando decimos que citemos una hora antes para que llegue el personal.

La logística debe ser para los colombianos algo así parecido a lo que fue desde un principio el concepto de calidad para los japoneses, como algo que hace parte de su propia existencia, estando dispuestos a cambiar para mejorar permanentemente en todos los aspectos y actividades humanas. Debemos grabarnos en la mente los cinco objetivos funcionales de la logística y de la distribución física en particular, lugar preciso, junto a tiempo, cantidad requerida, mejor calidad y costo razonable, para cumplirlas a cabalidad".

\section{La investigación en Logística}

\section{Por Luis Francisco López}

"El acto investigativo es la forma en que el ser humano establece una relación racional con su entorno y le permite cambiarlo y adaptarlo a su propia existencia ( no siempre con resultados positivos). Toda actividad que el ser humano realiza es susceptible de ser modificada con el fin de que se adapte mejor a una situación o a unos objetivos determinados; en este orden de ideas, el proceso investigativo proporciona una base válida de trabajo al ayudar a contestar los interrogantes básicos: ¿Qué? ¿Por qué? ¿Para qué?

El entorno empresarial no es diferente, aunque en nuestra realidad como país la relación academiaempresa no esté muy desarrollada. En un mundo cambiante las corporaciones globales enfrentan el reto de evaluar y configurar sus sistemas y estrategias de producción y distribución mientras buscan reducir costos, servir más que satisfactoriamente a sus clientes y aumentar sus utilidades después de impuestos (1). Es en este contexto que la logística como área de estudio responde a las necesidades del mundo empresarial pero, en un entorno que evoluciona, la logística también debe hacerlo.

A lo largo y ancho de la geografía mundial corporaciones y universidades, a través de sus centros de estudio e investigación, estrechan lazos para responder el desafío de la logística global. No es sencillo nombrar todas las áreas y temas tratados en la investigación en logística y esto sería en sí una ardua tarea investigativa. La lista que se presenta a continuación es el resultado de consulta de fuentes bibliográficas y en parte refleja la opinión del autor; es por esto que se debe aclarar al lector que se trata de una visión limitada y subjetiva.

Ya que la preocupación principal es la obtención de utilidades (aumento de ingresos y disminución de costos) aumentando a la vez la satisfacción de los clientes procurando reducir el impacto negativo sobre el medio ambiente, la investigación en logística se ha enfocado en gran medida en el desarrollo de modelos matemáticos que permitan la optimización del uso de los recursos disponibles (tanto físicos como informáticos). Los siguientes son algunos de los temas en que se ha enfocado el esfuerzo investigativo:

- $\quad$ Diseño de redes (Network Desingn). Se usa para mejorar la cobertura de los servicios y la distribución física. Pueden incluir restricciones variadas como capacidad de los recursos, ventanas de tiempo, flotas no homogéneas, demandas y tiempos estocásticos, rutas no factibles o con dirección, entre otras.

- $\quad$ Programación de operaciones (Sheduling). Trata de la asignación de tareas a recursos, y pueden ir desde la programación de operaciones en manufactura (asignar tarea a máquinas), hasta la asignación de personal (por ejemplo, de tripulaciones en aerolíneas) y la gestión de proyectos, entre otros". 